\title{
The impact of an Oral Health Education (OHE) program by teachers and mothers on adolescents' oral health
}

\author{
Sally Talib Da'aj, B.D.S. ${ }^{(1)}$ \\ Zainab A. Al- Dahan, B.D.S., M.Sc. ${ }^{(2)}$
}

\begin{abstract}
ABSRTACT
Background: Adolescence is one of the most dynamic stages of human development. However, Oral health is an integral part of public health, significantly impacts on the quality of life. OHE program is an important issue that should be given to them. The aim of this study was to evaluate oral health outcomes on adolescents' oral health by teachers and mothers

Materials and Methods: The study was carried out in seven schools of Diyala - Baquba city. This 14-weeks duration study assessed the effectiveness of school OHE program on oral hygiene status, gingival health, and halitosis assessment of 80, 12 year-old, both genders of school adolescents. From the selected schools, one group was supervised by the teachers and the other was supervised by the mothers. General and oral health assessments were evaluated using a questionnaire. A three days training workshop was organized for the teachers and mothers. Oral hygiene, gingival health, and halitosis assessment were assessed using plaque indices, gingival indices and halitosis scores respectively. the resulting data were statistically analyzed using SPSS version 20.

Results: Plaque, gingival and halitosis scores reductions were highly significant. Results recorded gingival index, and halitosis scores were lower among the teacher-led group compared to the mother-led group. Statistically, high significant differences were found $(P<0.01)$.But there is no significant differences were noticed between the groups for plaque index ( $p>0.05)$.

Conclusions: The OHE program was effective in teacher-led group than mother-led group in improving oral hygiene status, gingival health and halitosis scores of adolescents.

Keywords: adolescence, halitosis, mother-led, oral health education, oral hygiene status, teacher-led. (Received: 3/11/2018; Accepted: 28/11/2018)
\end{abstract}

\section{INTRODUCTION}

The mouth is a mirror of health and disease that partly occurs in the rest body because all oral examinations can distinguish signs of several general health problems, like nutritional deficiencies and systemic diseases. As well, there is increasing evidence that oral health complications not only reflect general health conditions but also getting worse and even initiating them ${ }^{(1)}$. Since the mouth is part of the body, a child's risk of oral disease cannot be separated from responsibility of the disease in general ${ }^{(2)}$. Likewise, a child's risk of general illness and dental disease in particular cannot be isolated from family and community disease risk. Thus, any realistic model of children's oral health outcomes should include a multilevel perception (3). Oral Health is essential to overall health, Health education is an important approach in the process of achievement of behaviours that important location for promoting health ,as they

(1) Ministry of health, Baghdad, Iraq

(2) Professor, Department of Pedodontics and Preventive Dentistry, College of Dentistry, University of Baghdad. reach over billion children worldwide and promote and maintain health ${ }^{(4)}$. School provide an wellbeing and quality of life ${ }^{(4)}$. General health which affected by some behaviours such as use of tobacco, excessive alcohol use and poor dietary choices are also associated with poor oral health outcomes. The appearance of this connection between oral health and general health and risk factors supports that the oral health care as an essential component of health programs and policies ${ }^{(5)}$. Untreated oral diseases in children commonly lead to serious general health problems, significant pain, and interference with eating and lost school time ${ }^{(6,7)}$. Numerous dental problems in children and adolescents have been negatively related with psychosocial well-being. Dental pain affects emotional stability of the children and registration in social activities such as preventing the children from engaging in playing ${ }^{(8)}$.

, through them, the school staff, families and the community as a whole ${ }^{(9)}$. The OHE can be effective in increasing knowledge in the short term and to some extent, behaviour such as tooth brushing and healthy eating (10). For all of the above and in order to increase the knowledge about the oral health, this study was designed. 


\section{MATERIALS AND METHODS \\ Study population}

This study was designed with 14-weeks intervention trial involving a representative sample of 12 years old adolescents of seven primary schools in Diyala - Baquba city. The sample involved forty adolescents as a teacherled group and forty as a mother-led group.

Ethical aspects

The permission to carry out the study was obtained from Diyala Educational Directorate and written consent was obtained from parents of the adolescents.

\section{Theoretical model of the study}

Data collection before implementation of the

OHE program

The data included the children's clinical dental examinations at baseline, as well as a selfadministered questionnaire for the adolescents at baseline.

\section{Questionnaires}

A self-designed format was designed to get general information regarding their general and oral health. The questionnaires were completed by the parents in their home.

\section{Clinical examination}

The children were examined in the classroom during school time and were seated on a portable chair. Portable lamp source for artificial illumination was used. A researcher recorded the clinical data on prepared data sheets. Eight clinical oral examinations were carried out by the researcher to evaluate the OHE program including:-Baseline examination carried out before conduction of the OHE program, and seven examinations carried out each two weeks after the implementation of the program. Baseline plaque index ${ }^{(11)}$, calculus component of periodontal disease Index was scored utilizing the criteria of Ramfjord (12), and gingival index (13) were recorded on Ramfjord teeth to assess the oral health status, and gingival health using a mouth mirror and a probe. Assessment of halitosis by a halimeter according to the manufacturer's instructions.

\section{Evaluation of the interventions}

It began two weeks after implementation of OHE program to assess PLI, GI, and halitosis scores again and continue after that two weeks interval for seven times.

\section{Interventional part of the study}

The trial involved two groups; both of them received the OHE program. The teachers and the mothers were given a single educational input to conduct $\mathrm{OHE}$ and explain the purpose of the study to the adolescents. The selected teachers and mothers were trained for oral hygiene education program by organizing one-hour session for three days, then made a calibration for them.

Training was in the value of teeth and general health, diet, nutrition, oral anatomy and tooth development, causes and prevention of dental caries and periodontal disease, oral malodour, and emergency oral care at school ${ }^{(14)}$.

The educational material provided to adolescent included posters, videotapes, macromodels, puppet theatre, coloring drawings in order to increase motivation and participation of adolescents. The videotapes contain a demonstration on the proper technique of flossing were shown by using the laptop. In demonstration of oral hygiene procedures macromodels (dentures, brush and floss) were used. Puppet theatre in the school plays an important role in transforming the educational material of dry matter to easy and more acceptable to learners ${ }^{(15)}$. Statistical Analysis

Data were entered onto Microsoft Excel and statistically analyzed using SPSS version 20 software. According to the central limit theorem, in large samples (>30or40), the sampling distribution tends to be normal, regardless of the shape of the data ${ }^{(16)}$. The collected data were grouped and illustrated in tables, and the following statistical tests were carried out.

Levene's Test procedure was used to find the homogeneity among the data.

Post hoc tests were used with a significant F-test and additional exploration of the differences among means is needed to provide specific information on which means and Scheffe's test were used in case of equal variances were assumed

P-values less than 0.05 were considered as statistically significant and P-values more than 0.05 were regarded as not significant, while Pvalues less than 0.01 were considered as a highly significant.

\section{RESULTS}

The Sample

The total sample consisted of 80 adolescents aged 12 years, 41 were males $(51.25 \%)$ and 39 were females $(48.75 \%)$ divided into two groups, (Table 1).

Table 1: Distribution of the sample according to teacher-led and mother-led groups 
$\mathrm{A}=$ group supervised by the teacher, $\mathrm{B}=$ group supervised by the mother

\begin{tabular}{|c|c|c|c|c|c|c|}
\hline Groups & No. of males & No.\% & $\begin{array}{c}\text { No. of } \\
\text { females }\end{array}$ & No.\% & Total No. & No.\% \\
\hline A & 20 & 25 & 20 & 25 & 40 & 50 \\
\hline B & 21 & 26.25 & 19 & 23.75 & 40 & 50 \\
\hline Total & 41 & 51.25 & 39 & 48.75 & 80 & 100 \\
\hline
\end{tabular}

\section{Before giving the OHE program:}

\section{Dental plaque, gingival health condition and} halitosis assessment

Table 2 revealed the mean value and the standard deviation of the plaque index, gingival index and halitosis scores for the sample among the groups at baseline examination. According to Levene's test, statistically no significant differences were noticed between the groups for each variable $(\mathrm{p}>0.05)$.

For calculus index, the study indicated no presence of calculus.

Scheffe repeated measure test between groups, according to mean differences showed that there were no significant differences $\mathrm{P}>0.05$, (Table 3 ).

Table 2: The mean values of the variables of the sample among the groups at baseline examination

\begin{tabular}{|c|c|c|c|c|c|c|}
\hline \multirow{2}{*}{ Groups } & \multicolumn{2}{c|}{ A } & \multicolumn{2}{c|}{ B } & \multicolumn{2}{c|}{ Levene's test } \\
\cline { 2 - 7 } Variables & Mean & $\pm S D$ & Mean & $\pm S D$ & F & p-value \\
\hline PLI & 2.1625 & 0.37 & 2.2000 & 0.39 & 0.155 & 0.694 \\
\hline GI & 1.6750 & 0.53 & 1.8125 & 0.50 & 0.081 & 0.777 \\
\hline Halitosis scores & 2.5750 & 0.67 & 2.7750 & 0.90 & 3.767 & 0.056 \\
\hline
\end{tabular}

Degree of freedom $(\mathrm{df})=1, \mathrm{~A}=$ group supervised by the teacher, $\mathrm{B}=$ group supervised by the mother

Table 3: Comparison by Scheffe test between the groups according to variables at baseline examination

\begin{tabular}{|c|c|c|}
\hline Variables & Mean difference & Sig. \\
\hline PLI & -0.375 & 0.974 \\
\hline GI & -1.375 & 0.659 \\
\hline Halitosis scores & -0.200 & 0.686 \\
\hline
\end{tabular}

Mean difference $=$ mean of group A - mean of group B

\section{After giving the OHE program \\ Dental plaque}

Figure 1 shows the means of plaque, gingival, and halitosis scores of the sample at different examinations before and after implementation of the OHE program. At baseline examination, the group A has 2.16 \pm 0.37 , $1.67 \pm 0.53,2.57 \pm 0.67$ for PLI, GI, and halitosis scores respectively and the group $\mathrm{B}$ has $2.20 \pm 0.39,1.81 \pm 0.50,2.77 \pm 0.90$ for PLI, GI, and halitosis scores respectively. At the seventh examination after 14weeks from starting giving the OHE program, group A has 1.87 \pm 0.40 , $1.39 \pm 0.42,1.82 \pm 0.54$ for PLI, GI, and halitosis scores respectively, it had been found that there 
were reduction in PLI, GI and halitosis scores while, there were increasing in the PLI, GI, and halitosis scores for the B group as 2.05 \pm 0.45 , $1.70 \pm 0.49,2.52 \pm 0.75$ for PLI, GI, and halitosis scores respectively. Levene's test of plaque index shows that there were no significant differences between baseline and seventh examinations for all the scores except for PLI in the seventh examination.

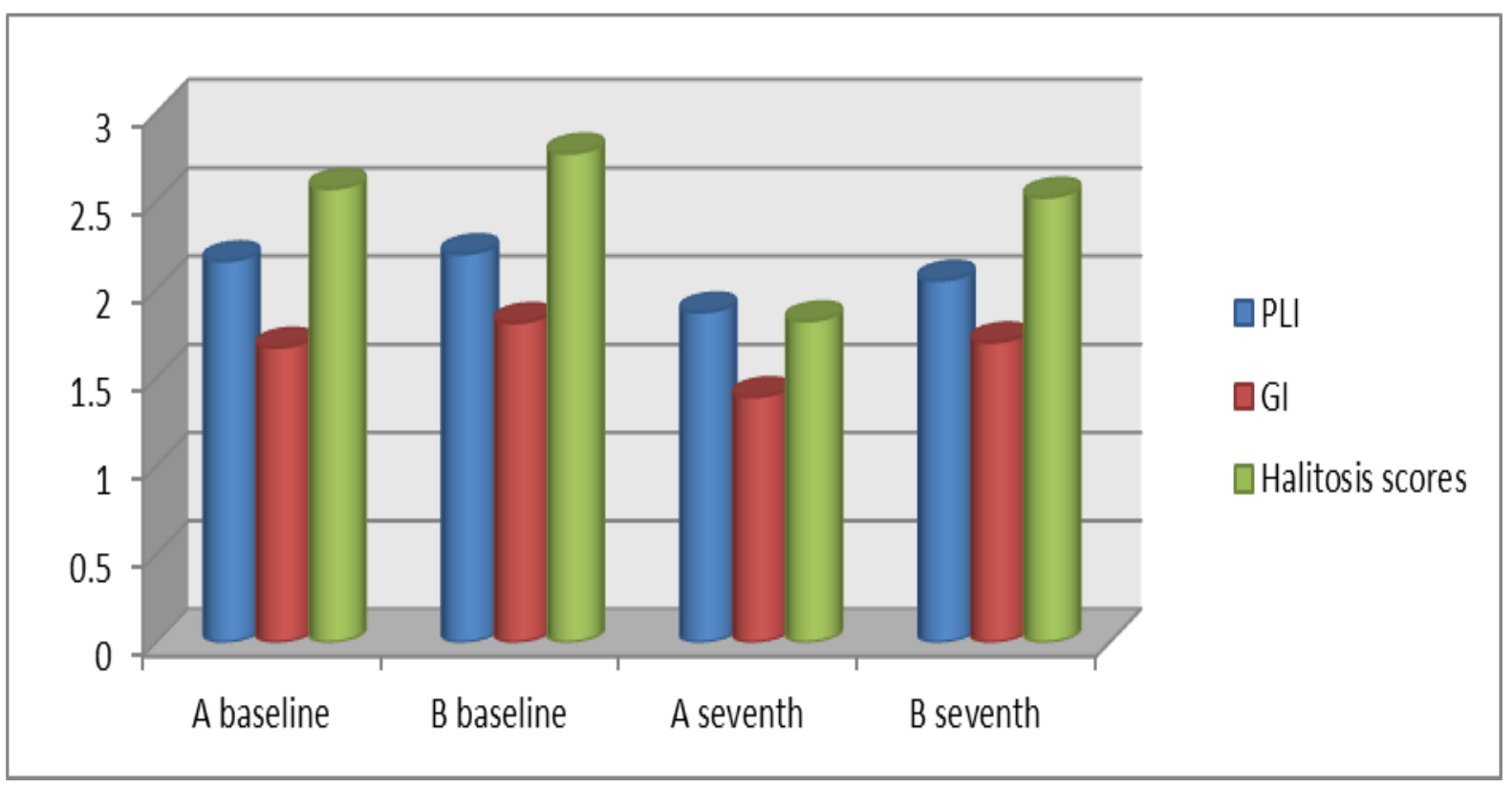

Figure 1: The mean values of the variables of the sample among the study groups

Scheffe test for compound comparison showed that there were statistically high significant differences in GI, and halitosis scores between the baseline and the seventh examination but there is no significant differences in PLI, (Table 4).

Table 4: Multiple comparisons by Scheffe test

\begin{tabular}{|c|c|c|c|}
\hline Variable & Examination & Mean difference & Sig. \\
\hline \multirow{2}{*}{ PLI } & First & -0.375 & 0.974 \\
\cline { 2 - 4 } & Seventh & -0.175 & 0.329 \\
\hline \multirow{2}{*}{ GI } & First & -1.375 & 0.659 \\
\cline { 2 - 4 } & Seventh & -0.312 & $0.016^{* *}$ \\
\hline \multirow{3}{*}{ Halitosis score } & First & -0.200 & 0.686 \\
\cline { 2 - 4 } & Seventh & -0.700 & $0.000^{* *}$ \\
\hline
\end{tabular}

** Highly significant $p \leq 0.01$, Mean differences $=$ mean of group A - mean of group B

Scheffe test was done to find the differences in favor of any of the groups. The mean value for group $\mathrm{A}$ is the lower one for all variables, (Table 5). Therefore, it could be argued that group $\mathrm{A}$ is more effective in the full improvement than group B. 
Table 5: Comparison of the means of groups according to Scheffe test at seventh examination

\begin{tabular}{|c|c|c|c|c|}
\hline Variables & Groups & No. & 1 & 2 \\
\hline \multirow{2}{*}{ PLI } & $\mathrm{A}$ & 40 & 1.87 & \\
\cline { 2 - 5 } & $\mathrm{B}$ & 40 & & 2.05 \\
\hline \multirow{2}{*}{ GI } & $\mathrm{A}$ & 40 & 1.39 & \\
\cline { 2 - 5 } & $\mathrm{B}$ & 40 & & 1.70 \\
\hline \multirow{2}{*}{$\begin{array}{c}\text { Halitosis } \\
\text { scores }\end{array}$} & $\mathrm{A}$ & 40 & 1.82 & \\
\cline { 2 - 5 } & $\mathrm{B}$ & 40 & & 2.52 \\
\hline
\end{tabular}

$\mathrm{A}=$ group supervised by the teacher, $\mathrm{B}=$ group supervised by the mother, No.= number, $1=$ the lower mean value, $2=$ the higher mean value

\section{DISCUSSION}

In this study, the selection of the age group 12 could be related to that this age group was the pubertal so that the several hormonal changes could occur ${ }^{(17)}$. Several epidemiological studies revealed that the periodontal disease is widespread in children and may vary from community to another ${ }^{(18)}$. Other study has been reached different results ${ }^{(19)}$. The effect of the program has been evaluated clinically as changes by means of indices, in oral hygiene effectiveness, gingival health, and halitosis assessment leading to evaluate the OHE program. In the present study, although the two groups were balanced in terms of oral hygiene at baseline examination, they reflect poor oral health because the children do not have any interest or knowledge about cleaning their teeth. It is important to say that this study found that the calculus was absent in these two group. This result does agree with other studies ${ }^{(20,21)}$, and disagree with an Iraqi study ${ }^{(22)}$. Several previous studies found that dental knowledge effected on the oral hygiene ${ }^{(20,21)}$, and other study found that the dental knowledge and behaviour does not affected the oral hygiene (23). It can be concluded that good oral hygiene habits tend to decrease the prevalence of halitosis in accordance with an Iraqi study ${ }^{(24)}$.

Generally, the adolescents neglected their teeth as showed by others ${ }^{(25,26)}$. However, no statistically significant difference was found between all groups at baseline examination.

The group supervised by teacher has the lower means of PLI, GI, and halitosis scores reflecting the increase in group's leader awareness and participation. The teacher-led group was due to the dynamic interaction between the teacher and specific students group. The teachers knew about the poor dental conditions in children and wanted to become involved in OHE. This study is agree with other study ${ }^{(27)}$ which suggested that the teachers had positive attitudes toward enlightening the parents about the importance of oral hygiene and teaching the children about preventive dentistry, while that they were less motivated about being involved in dental health school programs.

At the level of influence of the teachers on the adolescents, the current study goes with other investigators ${ }^{(28,29)}$ who specified that the majority of teachers demonstrated positive oral health attitude in the regard of their own involvement in the school-based dental health education because teachers believe that dental hygiene education is crucial for students' wellbeing as mentioned by other researcher ${ }^{(4)}$. While this study is incompatible with other researcher (30) who conducted that primary school teachers have a poor attitude to oral health issues. The results indicate that the effect of OHE program were effective in improving the students' knowledge and practices toward oral health.

The present results represent the important role of parents in improving and supporting the oral health status and behaviour of their offspring. As a result mothers should be empowered in their parenting and have more effective communication with their sons as mentioned by other study ${ }^{(31)}$.

The parents have got an important role in improving and maintaining the oral health status and behaviour of the children. This finding goes in line with other studies ${ }^{(10,32-34)}$ because the support by family is crucial in the development of children's habits in relation to health. Childrenparents cooperation was considered an important component of the present oral hygien education program. The mothers were invited to schools in order to encourage them for high responsibility with regard to their child's teeth as stated by other researchers $(35,36)$ and the health-promotimg school program had a positive effect on oral health knowledge and attitudes of mothers, also this proved by other study ${ }^{(4)}$.

The mothers through their behaviour served as an important model for everyday life, revealed by other study ${ }^{(37)}$. Adolescents also 
benefited from a close and supportive relationship with their parents for development of their oral hygiene performance, revealed by other study ${ }^{(38)}$.

\section{REFERENCES}

1. Initiative $\mathrm{CoaOH}$. Advancing oral health in America: National Academies Press; 2011.

2. Gansky S, Cheng N, Pollick H. Predicting early childhood caries with individual, family and neighborhood factors. International Association of Dental Research 83rd General Session. 2005.

3. Tellez M, Sohn W, Burt BA, Ismail AI. Assessment of the relationship between neighborhood characteristics and dental caries severity among lowincome African-Americans: a multilevel approach. Journal of public health dentistry. 2006;66(1):30-6.

4. Kwan SY, Petersen PE, Pine CM, Borutta A. Healthpromoting schools: an opportunity for oral health promotion. Bulletin of the World Health organization. 2005;83(9):677-85.

5. Scully C. Oral health in America: a report of the Surgeon General. 2000.

6. Gathecha G, Makokha A, Wanzala P, Omolo J, Smith P. Dental caries and oral health practices among 12 year old children in Nairobi West and Mathira West Districts, Kenya. Pan African Medical Journal. 2012;12(1).

7. Mafuvadze BT, Mahachi L, Mafuvadze B. Dental caries and oral health practice among 12 year old school children from low socio-economic status background in Zimbabwe. Pan African Medical Journal. 2013;14(164).

8. Smyth E, Caamaño F, Fernández-Riveiro P. Oral health knowledge, attitudes and practice in 12-yearold schoolchildren. Medicina Oral, Patología Oral y Cirugía Bucal (Internet). 2007;12(8):614-20.

9. Bica I, Cunha M, Reis M, Costa P, Costa J, Albuquerque C. Educational intervention for oral health. Procedia-Social and Behavioral Sciences. 2015;171:613-9.

10. Shenoy RP, Sequeira PS. Effectiveness of a school dental education program in improving oral health knowledge and oral hygiene practices and status of 12-to 13-year-old school children. Indian Journal of Dental Research. 2010;21(2):253.

11. Silness J, Löe H. Periodontal disease in pregnancy II. Correlation between oral hygiene and periodontal condition. Acta odontologica scandinavica. 1964;22(1):121-35.

12. Ramfjord SP. Indices for prevalence and incidence of periodontal disease. Journal of periodontology. 1959;30(1):51-9.

13. Löe H, Silness J. Periodontal disease in pregnancy I. Prevalence and severity. Acta odontologica scandinavica. 1963;21(6):533-51.
14. NYANDINDI U, MILÉN A, PALIN-PALOKAS T, ROBISON V. Impact of oral health education on primary school children before and after teachers' training in Tanzania. Health Promotion International. 1996;11(3):193-201.

15. Jurkowski H. Aspects of puppet theatre: Palgrave Macmillan; 2014.

16. Ghasemi A, Zahediasl S. Normality tests for statistical analysis: a guide for non-statisticians. International journal of endocrinology and metabolism. 2012;10(2):486-9.

17. Abdul-Ameer A. Stressful life events in relation to oral health condition and selected salivary constituents among 17-18 years old secondary school students

18. in Baghdad City/Iraq: College of Dentistry/Baghdad University; 2015.

19. Organization WH. Oral health surveys: basic methods: World Health Organization; 2013.

20. Al-Alousi W, Al-Sayyab M. Plaque, gingival condition and brushing behavior in 15-years old Iraqi school children in central region of Iraq. Iraqi Dent J. 1996;8(1):127-37.

21. Al-Eissa D. Oral health status of preschool children aged 3-5 years old and its relation to their socioeconomic status, and parent dental knowledge, behavior and attitude in two different social areas in Baghdad city. A master thesis, College of Dentistry, University of Baghdad. 2004.

22. Chaloob EK. Oral health status, dental knowledge and behaviors among children and adolescents (8-15) years old in the cities of Baghdad and Thamar. Journal of Baghdad College of Dentistry. 2013;25(4):100-3.

23. Al-Azawi L. Oral health status and treatment needs among Iraqi 5 years old kindergarten children and 15 years old students (national survey): PhD. Thesis. College of Dentistry, University of Baghdad; 2000.

24. Chu C, Fung D, Lo E. Dental caries status of preschool children in Hong Kong. British dental journal. 1999;187(11):616-20.

25. Hasan GA. Oral hygiene practices and self-perceived halitosis among dental students. Journal of Baghdad College of Dentistry. 2014;26(3):58-62.

26. Coolidge T, Heima M, Johnson EK, Weinstein P. The dental neglect scale in adolescents. BMC Oral Health. 2009;9(1):1.

27. Eick S, Pietkiewicz M, Sculean A. Oral microbiota in Swiss adolescents. Clinical oral investigations. 2013;17(1):79-86.

28. Sgan-Cohen HD, Saadi S, Weissman A. Dental knowledge and attitudes among Arab schoolteachers in northern Israel. International dental journal. 1999;49(5):269-74.

29. Ehizele A, Chiwuzie J, Ofili A. Oral health knowledge, attitude and practices among Nigerian primary school teachers. International journal of dental hygiene. 2011;9(4):254-60. 
30. Ramroop V, Wright D, Naidu R. Dental health knowledge and attitudes of primary school teachers toward developing dental health education. West Indian Medical Journal. 2011;60(5):576-80.

31. Sofola O, Agbelusi G, Jeboda S. Oral health knowledge, attitude and practices of primary school teachers in Lagos State. Nigerian journal of medicine: journal of the National Association of Resident Doctors of Nigeria. 2001;11(2):73-6.

32. Saied-Moallemi Z. Oral Health among Iranian Preadolescents: A School-Based Health Education Intervention. 2010.

33. Desforges C, Abouchaar A. The impact of parental involvement, parental support and family education on pupil achievement and adjustment: A literature review: DfES Publications Nottingham; 2003.

34. Pine CM. Designing school programmes to be effective vehicles for changing oral hygiene behaviour. International Dental Journal. 2007;57(S5):377-81.

35. Saied-Moallemi Z, Virtanen J, Vehkalahti M, Tehranchi A, Murtomaa H. School-based intervention to promote preadolescents' gingival health: a community trial. Community dentistry and oral epidemiology. 2009;37(6):518-26.
36. Moysés ST, Moysés SJ, Watt RG, Sheiham A. Associations between health promoting schools' policies and indicators of oral health in Brazil. Health Promotion International. 2003;18(3):209-18.

37. Petersen PE, Peng B, Tai B, Bian Z, Fan M. Effect of a school-based oral health education programme in Wuhan City, Peoples Republic of China. International dental journal. 2004;54(1):33-41.

38. Okada M, Kawamura M, Kaihara Y, Matsuzaki Y, Kuwahara S, Ishidori H, et al. Influence of parents' oral health behaviour on oral health status of their school children: an exploratory study employing a causal modelling technique. International Journal of Paediatric Dentistry. 2002;12(2):101-8.

39. Aleksejūnienė J, Brukienė V. Parenting style, locus of control, and oral hygiene in adolescents. Medicina (Kaunas). 2012;48(2):102-8.

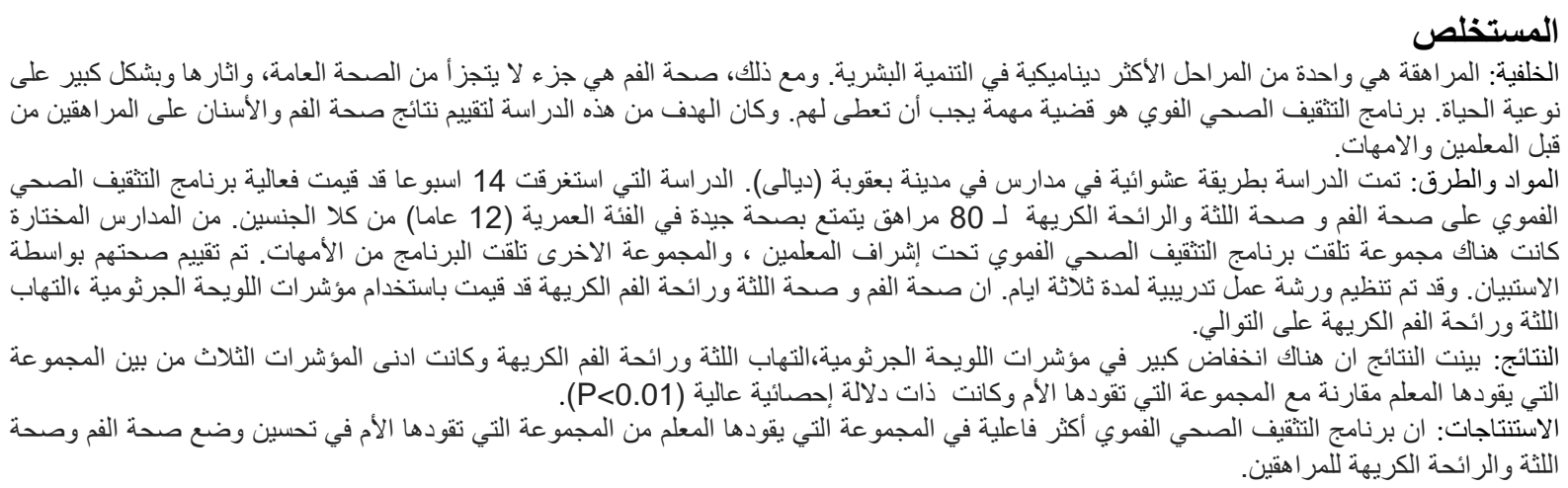

